\title{
REPENSANDO A IDENTIDADE CULTURAL LATINO-AMERICANA A PARTIR DO FILME QUÉ TAN LEJOS
}

\section{ADRIANA TEIXEIRA PEREIRA}

RESUM 0: A cinematografia com a sua linguagem imagética universal consegue captar e refletir a realidade circundante. Desse modo, pretendemos analisar as questões relativas à identidade cultural latino-americana a partir do filme equatoriano "Qué tan lejos", dirigido por Tania Hermida (2006), à luz dos estudos culturais de Hall (2015) e García Canclini (2008), buscando problematizar as diferentes questões históricas, sociais e políticas que possam contribuir para o diálogo, valorização e fortalecimento de uma integração regional neste espaço cultural que é América Latina.

PALAVRAS-CHAVE: cinema; interculturalidade; identidade cultural latino-americana; Tania Hermida.

\section{INTRODUÇÃO}

Falar sobre a identidade latino-americana é uma difícil tarefa, já que os países que integram a América Latina são dotados de uma grande diversidade cultural. No entanto, apesar desta multiplicidade na constituição de cada povo, há vários aspectos em comum possíveis de elencar na constituição dessa identidade: reconhecimento de pertencer a uma mesma região geográfica, aspectos em relação à história de conquista e de submissão, dizimação de populações autóctones, lutas pela independência, mobilização cultural tardia etc. Há, portanto, uma unidade nessa diversidade (LARRAÍN, 1994).

A motivação para desenvolver esta investigação foi baseada em um interesse constante por entender e discutir questões do ser latino-americano na nossa vida 
cotidiana e, assim, contribuir para a diminuição das muitas imagens superficiais e estereotipadas que nós, brasileiros, de maneira geral, apresentamos sobre América Latina, além do não pertencimento dentro desse espaço cultural. A partir das diferentes manifestações culturais, neste caso, a cinematografia, é possível sensibilizar para diferentes questões históricas, sociais, políticas, estabelecendo um paralelo com a nossa realidade, constantemente fixando uma relação de similitude, diversificação e comparação. O filme que analisamos, por exemplo, trata de uma viagem pelo Equador feita por duas mulheres de nacionalidades diferentes, uma espanhola e outra equatoriana, que dão vazão para observar diferentes questões interculturais na construção da narrativa.Com base nisso, a pergunta que direciona este trabalho é: quais questões relativas à identidade cultural latinoamericana é póssível destacar a partir do filme equatoriano Qué tan lejos e como essas contribuem para um reconhecimento identitário latino-americano?

Em vista disso, o objetivo é identificar e problematizar a construção da identidade cultural latino-americana a partir do filme, contribuindo para uma discussão sobre a importância do diálogo com os países vizinhos, para a valorização dessa identidade e para um fortalecimento de uma integração regional.

\section{A BUSCA DA IDENTIDADE CULTURAL POR MEIO DE FILMES LATINO-}

\section{AMERICANOS}

A questão da identidade latino-americana é um tema que cada vez ganha mais espaço nos diferentes campos de estudos, já que o reconhecimento de uma unidade latino-americana é fundamental para cumprir determinados anseios neste cenário sociocultural da modernidade. Mas que traços são relevantes para a construção de uma identidade cultural da América Latina, tão complexa e plural?

De acordo com Irineu, "a latinidade não se direciona exclusivamente ao modo cultural e social de ser da América Latina, mas, de modo amplo, ao modo cultural e social de ser dos povos latinos" (IRINEU, p. 24), pelo reconhecimento dos modos de ser e agir em determinado contexto e também pelo modo de crer do outro, seja na igualdade ou diferença.

A escolha de um filme para discutir e ressignificar a construção e o reconhecimento da identidade latino-americana se deu por duas razões principais: em primeiro lugar, percebemos esse instrumento como uma fonte primária de acesso 
à cultura e à língua dos falantes nativos; segundo, pelo cinema ser um suporte extremamente atrativo para os jovens, visto que é um facilitador dinâmico de trabalho em sala de aula, e possibilita tratar de diferentes temas a partir de diferentes valores, crenças e comportamentos.

Assim, nosso ponto de partida é a defesa dos Parâmetros Curriculares Nacionais (PCN) sobre a compreensão do cinema como um recurso didático-pedagógico interdisciplinar para a formação crítica dos cidadãos, já que esse artefato cultural representa e recria o modo de viver e pensar da sociedade em questão. Nesse sentido, os professores precisam estar familiarizados com as possibilidades que o filme pode trazer para a discussão em sala de aula. Cruz, Gama e Souza (2006) afirmam que

\begin{abstract}
O cinema, com o seu aparato tecnológico apropriado para documentar, encenar e narrar histórias, nos permite uma nova maneira de olhar para o mundo e, com isso, estabelece uma forma peculiar de inteligibilidade e conhecimento. Dessa forma, podemos considerar que o texto fílmico atua na escola como sendo um recurso lúdico e extremamente sedutor, que atrai a atenção dos alunos e os envolve na realização das tarefas (CRUZ; GAMA; SOUZA, 2006, p. 489).
\end{abstract}

Em sala de aula, é imprescindível tratar a visibilidade da América Latina. O texto fílmico traz a ludicidade e a realidade para o tema. Nesse sentido, a ideia do artigo parte do intuito macro de fazer possível um trabalho didático com filmes para discutir, compreender e reconhecer-se como um indivíduo latino-americano.

O uso do cinema como instrumento de ensino-aprendizagem perpassa a ideia de língua-cultura que defende Mendes, pois, segundo a autora, “[...] tudo o que fazemos quando interagimos com o mundo através da linguagem é um modo de produzir cultura" (MENDES, 2012, p. 375). O filme, com a sua linguagem imagética universal, consegue captar e refletir a realidade que lhe é circundante, refletindo diferentes valores e crenças de determinada cultura. Assim, por meio desse objeto, é possível ter acesso a outra cultura que, por sua vez, é uma oportunidade de promover reflexões e condições para entender determinadas situações que acontecem nessas sociedades, de maneira crítica e respeitosa, impedindo a criação de estereótipos ou pré-julgamentos pelo diferente. 
De acordo com Lessa, “a língua é um lugar de experiências e práticas sociais que envolvem sujeitos atravessados por suas identidades sociais e relações de poder [...] suas identidades incidem na interação, em tensão com outras identidades” (LESSA, 2013, p.18), já que cada sujeito é permeado por seus valores culturais, políticos e ideológicos, que são manifestados em situações situadas social, histórica e culturalmente. É o que se pretende observar, portanto, na relação estabelecida pelas duas nacionalidades apresentadas do filme.

Compreendemos cultura, a partir de Hall e Jeferson, como "o modo pelo qual as relações sociais [permeadas de poder] de um grupo são estruturadas e moldadas, mas é também a maneira pela qual essas formas são experimentadas, entendidas e interpretadas" (HALL; JEFERSON, 1986, p.138). Nesse sentido, a cultura se vê entrelaçada ao conceito de identidade, porque:

\begin{abstract}
A construção de identidades vale-se de uma matéria-prima histórica, geográfica, biológica, pelas relações de poder as quais são produzidas e reproduzidas pela memória coletiva [...] um processo de construção de significado com base em um atributo cultural ou um conjunto de atributos culturais que se relacionam e prevalecem sobre outras fontes de significado. (CASTELLS, 1999, p. 23)
\end{abstract}

A identidade é construída e reconstruída num movimento que Hall chama de fragmentação do sujeito, “composta não de uma única, mas de várias identidades, algumas vezes contraditórias ou não resolvidas” (HALL, 2015, p. 11). É com base nessa fragmentação do ser que devemos ter cuidado ao tratar da identidade latino-americana. Portanto, neste artigo, não pretendemos encerrar o assunto, mas evidenciar a necessidade de uma discussão constante; tampouco queremos limitar a pluralidade cultural da América Latina a uma definição simplista, apenas queremos apontar aspectos dentro da variedade cultural, aqueles que são comuns entre os países dentro deste espaço cultural. De acordo com Larraín (1994), há uma unidade nessa diversidade. É pensando essa unidade que passamos para análise do filme. 
QUÉ TAN LEJOS ESTAMOS DA CONSTRUÇÃO IDENTITÁRIA LATINO-

AMERICANA?

Qué tan lejos (2006) é dirigido e roteirizado por Tania Hermida, equatoriana de Cuenca. Hermida estudou cinema na Escola Internacional de Cine e Televisão de San Antonio de los Baños (EICTV), em Cuba; dirigiu vários curtas metragens e, atualmente, trabalha em seu terceiro longa-metragem. Qué tan lejos, seu primeiro longa-metragem, foi um fenômeno no Equador e ganhou inúmeros prêmios. O drama conta a história de duas jovens, Tristeza e Esperança, que viajam juntas pelo Equador em uma jornada que vai muito além do conhecimento de paisagens e de pessoas, mas também retrata um percurso de autoconhecimento.

Essa produção nos permite fazer uma análise intercultural, a partir da perspectiva da nacionalidade das duas jovens protagonistas, uma equatoriana e outra espanhola. Além disso, também fazemos um paralelo com a nossa língua materna, percebendo a produção fílmica ou qualquer outra manifestação cultural na língua-meta como instrumento de acesso às diferenças e similitudes entre identidades, pois o filme retrata comportamentos socioculturais e históricos que configuram o indivíduo enquanto "ser multifacetado, mutante, capaz de assumir não apenas uma, mas várias identidades que vão sendo construídas na sua interação com o Outro e com o meio social, sempre num constante estado de fluxo" (MOITA LOPES, 2010).

Mas qual é essa identidade da qual estamos falando? Quando mencionamos, por exemplo, a questão da identidade, estamos tentando identificar elementos dentro da pluralidade cultural latino-americana que nos aproximam e nos configuram como unidade. Dessa forma, é possível pensar identidade em diferentes aspectos: como reconhecimento de pertencer a uma mesma região geográfica, ou em relação à história de conquista, submissão e dizimação de populações autóctones, lutas pela independência, mobilização cultural tardia, entre outras motivações. A partir disso, tentamos encontrar ao longo do filme elementos que representassem essas questões buscando em cada discurso referências históricas, sociais e/ou culturais. A produção fílmica, como mencionado anteriormente, tem essa capacidade de retrato, isto é, de se fazer conhecer por meio dos diálogos estabelecidos, das imagens, dos sons, entre outros. 
De acordo com Nuria Vidal, crítica de cinema, a produção fílmica apresenta "un sentido del ritmo ágil, unos diálogos deliciosos en sus contrastes y unos personajes entrañables en su simplicidad" (VIDAL, 2008, p. ?). Essa simplicidade está representada, inicialmente, na maneira como se construiu a apresentação das personagens. Cada primeira aparição é feita seguindo o modelo de uma ficha bibliográfica. Esse recurso pode ser uma estratégia de aproximação da personagem com o telespectador. A maneira como as informações são dispostas e elencadas faz com que o telespectador possa resgatar as suas próprias informações em um jogo de similitudes, diferenças e comparações, conforme trecho abaixo:

María Teresa Hernández Larrea, inscripta en el registro civil de Quito el o5 de noviembre de 1982. Hija de Augusto y Berta, abogado nacido en Ambato y maestra de música, descendencia lojana. ¿Peso al nacer? 2 kilos. ¿Edad del primer sangrado? 13 años y medio. ¿Patologías familiares importantes? Abuela materna fallecida con cáncer en los senos a los 70 años; abuelo paterno alcohólico (QUÉ TAN LEJOS, 2006, 06 m 04 s).

O primeiro ponto a ser destacado, a partir da fala de Tristeza, seguida também por suas ações (balanço de cabeça, olhos virados, escusas etc.) é a postura confiante e animada da turista espanhola Esperança: "Que todo te parece muy guay. Este es un país que tiene problemas también. Hay un paro.” (QUÉ TAN LEJOS, 2006). Nesse trecho, é possível depreender o posicionamento de Tristeza, uma jovem universitária, consciente e crítica da realidade da qual faz parte, com relação à construção do "ser turista" que ela tem compreendido como um sujeito superficial, ingênuo e desinformado e, portanto, distanciado da realidade. Muitas vezes, inclusive, reduz suas expectativas a um modelo perfeito e simétrico do lugar e da cultura. No entanto, esta generalização vai sendo desconstruída, ao longo do filme, nas diferentes circunstâncias de diálogos, que tratam de maneira sensível e profunda as relações históricas, sociais e culturais que configuram a identidade social dos grupos apresentados.

Outra questão muito forte no filme diz respeito à relação que se estabelece entre Equador e Espanha, enquanto colonizador e colonizado:

\section{Esperanza: ¿Cuánto te debo?}


Taxista: 15 sería.

Esperanza: ¿15? Pero el taxímetro ha marcado 8.

Taxista: Sí, señorita. Pero usted salió del aeropuerto internacional. Ahí la tarifa cambia.

Esperanza: Ay. [Resopla y le entrega al taxista el billete]

Taxista: Señorita, ¿̇no tiene los cinco? Es que no tengo sueltos, oiga... pero no creo que le importe los 5 dolaritos, ¿̇no? Total ustedes allá los hace en miles.

Esperanza: ¿Allá adónde?

Taxista: Allá en España, pues. Se nota clarísimo que es de allá, pues.

Esperanza: ¿Y quién te ha dicho que en España se gana mucho?

$[\ldots]$

Esperanza: Pues en Barcelona ganamos sueldo igual que tú, trabajando 4oh a la semana.

Taxista: 4oh. Poquito.

Esperanza: Adiós. Va a robo, tío.

Taxista: ¿Cómo dice? ¿Robo? Robo es lo que le paga a mi hermano por recoger brócolis todo el año. Bien decía mi tío - que hay que tener cuidado con ustedes españoles... Ya se fue llevando todo el tesoro de los incas. Viene hechos muy... muy... (QUÉ TAN LEJOS, 2006, 03 m 56 s).

A partir dessa construção apresentada no filme, é possível refletir sobre o passado e resgatar o fato ainda atual da concepção de modernidade/colonialidade (MIGNOLO, 2005). A primeira fala do taxista evidencia um imaginário comum e equivocado de modernidade, isto é, de que a Espanha, enquanto Europa, é um lugar de fartura, de fortaleza, dos melhores empregos, dos melhores estudos, de um mundo civilizado. No segundo momento, o taxista se vê aborrecido com a resposta de Esperança, que discorda do valor cobrado da corrida. Nesse diálogo, fica evidente o ressentimento, enquanto latino-americano, pelo que Espanha fez no período da colonização. Tal reação representa um movimento muito forte da necessidade de rever nossas raízes e lutar para um reconhecimento identitário, uma busca de espaço nesta modernidade tardia, no qual seja possível depreender-nos do massacre que sofremos e nos coloquemos em condição de igualdade perante os grandes centros mundiais.

Para García Canclini, que defende a hibridização cultural da América Latina como elemento fundamental para compreender sua essência, a construção e o 
reconhecimento podem ser estabelecidos por meio de algumas agendas que podem colaborar para uma reconstrução, criativa e competitiva, como espaço cultural, em âmbito global: a) identificar as áreas estratégicas do nosso desenvolvimento, internamente, pensando ajustes e formas de potencializar as condições vidas da população; b) "desenvolver políticas socioculturais que promovam o avanço tecnológico e a expansão multicultural de nossas sociedades" (GARCÍA CANCLINI, 2008, p. 102); c) reestabelecer as relações de cooperação internacional a partir desta política cultural interna; e d) reconhecer e proteger a pluralidade latino-americana dentro deste movimento crescente de rompimento de barreiras acarretado pela globalização.

É importante destacar que a construção desse espaço cultural ainda está permeada pela lógica da colonialidade, como defende Walter Mignolo:

La idea de América es producto y consecuencia de esa ideología de la civilización y la expansión occidental. [...] "(Latino)américa" no es una entidad que puede observarse o experimentarse, sino una idea que se origina en los conflictos de interpretación de la diferencia colonial. [...] la relación entre los países industrializados, desarrollados, imperiales y los países en vías de industrialización, subdesarrollados y emergentes es la diferencia colonial en la esfera donde se establece el conocimiento y subjetividad, la sexualidad y el género, el trabajo, la explotación de los recursos naturales, las finanzas y la autoridad. Con la idea de que existen diferencias culturales se pasa por alto la relación de poder. (MIGNOLO, 2005, p. 61)

Desse modo, é preciso discutir e ressignificar a percepção do que é América Latina. Na concepção de Ramos (2012),

a identidade da América Latina é o primeiro e único caso da construção de uma identidade supranacional contínua baseada em uma história comum e civilização que, além da diferença, foi nutrida por lutas e paradigmas compartilhados que se reconfigura com os desafios atuais. [...] É uma síntese de civilização e culturas diversas e um compromisso ideológico, resultante de relações de força entre setores dominantes e setores dominados, que se concretiza em projetos hegemônicos e contextos geopolíticos concretos. (RAMOS, 2012, p. 51) 
Isso nos faz relembrar a ideia de descobrimento e/ou invenção que coloca Mignolo, em que ambos supõem apagados os povos originários. Para o autor, o descobrimento reflete a lógica da dominação imperialista, e a invenção levanta a possibilidade de uma nova interpretação do ponto de vista descolonial, no entanto, ainda invalidado o fato deste território e sua população já ser existente.

Esse posicionamento de colonizador/colonizado, saqueador de bens naturais, assassino de povos originários, único e possível evangelizador, também é visto na fala de Tristeza, quando esta complementa ironicamente o discurso de Esperança, que fala em defesa da Espanha, como indivíduo que comparte esta identidade nacional.

Esperanza: Aquí estoy en el panecillo, mira... con la virgen. Ah, esto es en el museo de cera. Estoy con los líderes de la independencia.

Tristeza: Los asesinados por los españoles. (QUÉ TAN LEJOS, 2006, 22 m 49 s).

Ou ainda no diálogo que se estabelece entre Esperança e os dois equatorianos, Tristeza e um barman, sobre a concepção do ser espanhol e equatoriano, e mais ainda de como é visto o espanhol pela ótica do equatoriano.

Barman: Eres típico de esos viajeros... esos de cable que van de excursión, pero nunca se despeinan.

Esperanza: Pues, tío, yo soy una viajera de cable. Pero este país, como cualquier otro, es muy bonito para que yo quiera estar pisando en mierda. Para eso, me quedo en el mío.

Tristeza: No compares a mi país con el tuyo.

Esperanza: Ah, no. ¿Y por qué no? Si los dos son una mierda.

Barman: Perdón, perdón, perdón... esto acá vendría a ser como otra mierda... otra. Tristeza: Por eso. Desde que llegaron tus antepasados, nos pisaron... no han parado de venir los piratas de todo el mundo. (QUÉ TAN LEJOS, 2006, $72 \mathrm{~m} 14$ s)

É importante destacar que a identidade do indivíduo pós-moderno se constrói e se define pela relação com o Outro, ou seja, "a mesmidade (ou a identidade) porta sempre o traço da outridade (ou da diferença)" (SILVA, 2014, p. 79). A identidade, neste caso, é marcada pela diferença, isto é, “eu sou o que sou, porque não 
sou o outro", havendo uma relação de dependência da diferença. Isso fica evidente no distanciamento e na demarcação de Tristeza, ao falar com Esperança, dos dois grupos diferentes - os equatorianos e os espanhóis.

É pensando nesta relação dialógica que nossas análises e nossas relações sociais precisam ser tratadas interculturalmente, porque além de atentar para as diversidades de mundos culturais, possibilitando reconhecimento e diálogo com as diferentes identidades dentro do sistema social, fazendo conhecer outros universos, outras formas de convivência e de cultura, também é necessário salientar que as relações entre diferentes culturas envolvem, "fundamentalmente, relações de poder" (SILVA, 2014, p. 96).

Estudar como se dá a construção identitária de um determinado povo é tentar encontrar aspectos que o caracterizam, levando em consideração, para além do histórico, aspectos sociais, políticos, culturais. A partir disso, em outra fala do filme, um professor em sala de aula tenta comentar questões que justificam a paralização no país.

Profesor: El Ecuador no se va a acabar por los terremotos sino por los malos gobiernos. [...] iQué viva la democracia! iAbajo el presidente!”. (QUÉ TAN LEJOS, 2006, $5 \mathrm{~m} 18 \mathrm{~s}$ )

Um dos aspectos de aproximação latino-americana está relacionado à configuração política desses países.

É essencial compreender que a década de 1960 [...] colocou no palco novos atores em papeis inéditos na história recente. A revolução mexicana já havia trazido ao cenário mundial protagonistas que desestabilizaram o modelo eurocêntrico, oligárquico, branco e patriarcal, pois se fundava na articulação de índios e mestiços, como líderes do movimento. (REIS, 2009, p. 21)

Ainda há uma luta constante por uma efetivação da democracia, mas uma democracia que se compreenda como uma política que coloque o povo como base e representante, verdadeira essência desse sistema político, e não uma democracia que siga servindo interesses da burguesia e das elites do mercado liberal. É, pois, fundamental que esse conceito seja compreendido para respaldar as lutas 
contra a hegemonia capitalista do sistema geopolítico e econômico na figura da Europa e dos Estados Unidos.

Também não podemos deixar de verificar no filme e, por sua vez, nos países da América Latina, uma concepção ainda patriarcal da posição da mulher na sociedade. Nas falas que seguem, é possível notar como a senhora equatoriana tem uma visão obsoleta sobre a mulher, ao ficar surpresa por Tristeza viajar sozinha pelo Equador. Seu espanto pode vincular-se a partir dos dados de violência na cidade, e, por conseguinte, da violência contra a mulher. Segundo os dados do Instituto Nacional de Estadística y Censos (INEC), de 2012, em Quito, por exemplo, 6 em cada 10 equatorianas sofreram algum tipo de violência ao longo de sua vida. Uma violência que é naturalizada por falta de políticas públicas que se preocupem com a independência, a liberdade, o progresso, a justiça e a igualdade social.

I. Una chiquita a Tristeza en la estación de buses.

"Chiquita: ¿Y dónde se va?

Tristeza: A Cuenca.

Chiquita: Ah... dicen que es bonito Cuenca. Mi primo vive allá. [sorpresa] ¿se va solita?

Tristeza: Sí, mon.

Chiquita: Mamá dice que no es bueno andar sola porque a uno le sale los demonios. Por eso lo que a mí... siempre con mis amigos. (QUÉ TAN LEJOS, 2006, 11 m 35 s )

II. Una mujer a Tristeza y Esperanza en el bus.

"Mujer adulta: Irán con cuidado, guaguas.

Esperanza: ¿’Por qué es peligroso?

Mujer adulta: No tanto, pero siempre dos mujeres solas" (QUÉ TAN LEJOS, 2006, $18 \mathrm{~m} 24 \mathrm{~s})$

III. Un joven que le jala dedo a Tristeza

Joven: ¿Le tiene miedo a los ecuatorianos o qué?

Tristeza: Oye... también soy ecuatoriana.

Joven: Es que no parece.

Tristeza: ¿Cómo así? 
Joven: Es que, para empezar, las ecuatorianas no andan solas. (QUÉ TAN LEJOS, 2006, $48 \mathrm{~m} \mathrm{29} \mathrm{s)}$

A generalização desta última personagem, ao mencionar que as equatorianas não andam sozinhas, mostra o reconhecimento de uma sociedade em que a imagem da mulher é inferiorizada quanto a seu direito de ir e vir. Portanto, ela é impossibilitada de fazer uma viagem sozinha pelo seu país.

Outro aspecto que nos chamou atenção diz respeito ao papel que a televisão ocupa na vida do equatoriano. Quando falamos de televisão, estamos nos referindo à televisão aberta, isto é, aquela em que a mídia representa diretamente interesses da burguesia e cumpre um papel fundamental de alienação da realidade. De maneira geral, isso acontece no Brasil e em diferentes países da América Latina.

Tristeza: Oiga, señora, ¿̇han dicho lo del paro en las noticias?

Mujer: No, no he escuchado nada.

Tristeza: ¿Y no saben a qué hora van abrir las carreteras? ¿En la tele no han dicho nada?

Mujer: De noche sabe dar las noticias.

Tristeza: Te enciende la tele. No sé malita. Capaz de se sabe algo.

Mujer: A esta hora no da nada de eso. Pero se quiere un día sabe dura los paros. [enciede la tele] ve... mi telenovela está empezando" (QUÉ TAN LEJOS, 2006, 39 m $57 \mathrm{~s})$.

Para Carmona, a televisão representa algo que visa "sobretudo, ao mercado de consumo, tendo como objetivo principal sua sustentação empresarial e lucratividade”(CARMONA, 2008). García Canclini corrobora tal posição ao afirmar que “'o que nos une é o que nos vendem'. As empresas fabricam não apenas bens úteis, mas também atitudes, estilos de vida e aparências pessoais, as marcas globalizadas vinculam milhões de consumidores" (GARCÍA CANCLINI, 2008, p. $32)$.

Esse tipo de consumo se relaciona com a compreensão de identidade cultural defendida neste artigo. Segundo pontua García Martínez, 
A identidade cultural se refere ao grau em que uma pessoa se sente conectada, parte de um grupo cultural, ao próprio grupo de referência no qual cresceu: inclui uma complexa combinação de fatores, tais como autoidentificação, sentido de pertencimento ou exclusão, desejo de participar de atividades de grupo (GARCÍA MARTÍNEZ, Apud PARAQUETT, 2010, p. 143).

Essa ideia de pertencimento ou exclusão de um grupo só é possível pelo compartilhamento das práticas sociais situadas historicamente. Desse modo, é necessário resgatar muitos aspectos que se apresentam no filme para melhor entender as relações de poder que são estabelecidas pelas personagens. O reconhecimento latino-americano, por exemplo, aparece muito forte no fim do filme, no discurso do Barman e no assentimento de todos os presentes na conversa:

Barman: "Acá no somos ni blancos, ni puros [...] Los que decimos que somos indios, no todos somos indios. Los que decimos que no somos indios, a veces sí somos. Los que no somos negros, a veces queremos ser negros. Los que somos... medio negros, medio indios o medio algo...” (QUÉ TAN LEJOS, 2006, 73 m 36 s)

Percebemos nessa fala uma perspectiva maior quanto às identidades latinoamericanas, semelhante àquela que se defende hoje, isto é, a de compreendê-las como híbridas (CANCLINI, 2008) e mestiças:

A identidade da América Latina é o primeiro e único caso da construção de uma identidade supranacional contínua baseada em uma história comum e civilização que, além da diferença, foi nutrida por lutas e paradigmas compartilhados que se reconfigura com os desafios atuais. [...] É uma síntese de civilização e culturas diversas e um compromisso ideológico, resultante de relações de força entre setores dominantes e setores dominados, que se concretiza em projetos hegemônicos e contextos geopolíticos concretos. (RAMOS, 2012, p. 51)

A construção da identidade latino-americana, nesse contexto, baseia-se na ideia de um imaginário que compartilha diferenças, mestiçagem e hibridismo. Contudo, conforme o próprio título do filme, qué tan lejos estamos de construir nossa identidade latino-americana? Qué tan lejos de nos reconhecer como vizi- 
nhos, com hermanos, como iguais dentro de outras tantas diferenças que nos distanciam? Esse filme consegue tratar de uma forma muito interessante e sutil a questão das distâncias e evidencia também o aspecto fundamental quando tratamos a concepção do ser latino-americano - a fluidez e a hibridação:

\begin{abstract}
Hay un acercamiento histórico que piensa a la identidad cultural como algo que está permanentemente siendo construido y reconstruido dentro de nuevos contextos y situaciones históricas y que no puede nunca decirse que está finalmente resuelta o constituida definitivamente como un conjunto fijo de cualidades, valores y experiencias comunes. (LARRAÍN, 1994, p. 62)
\end{abstract}

A partir dessa noção, podemos compreender toda esta pluralidade e fluidez da América Latina.

\title{
CONSIDERAÇÕES FINAIS
}

No filme analisado, Qué tan lejos, é possível reconhecer nos diálogos das personagens uma identidade cultural latino-americana. As personagens evidenciam muitas questões com as quais o público pode se ver identificado - o remorso de uma relação de colonialidade, os meios de comunicação vendidos que não atendem à necessidade nacional, a presença de um sistema patriarcal arraigado, um sistema político democrático frágil decorrente de um passado que lhes tirou autonomia e identidade nacional etc. A partir das questões teóricas e da análise apresentadas, acreditamos que a cinematografia é fundamental para repensar a identidade latino-americana, uma vez que ela é uma manifestação cultural e que é pela cultura que nossas ações e nossos comportamentos são moldados.

Além disso, relacionamos diferentes aspectos sobre essa identidade, problematizando percepções, ora superficiais e/ou estereotipadas, que cotidianamente estabelecemos. A produção fílmica escolhida permite um trabalho intercultural riquíssimo, pois integra mundos culturais diferentes. Destacamos também que, por meio do cinema, fomentamos o enriquecimento intelectual, proporcionando discussões mais amplas, plurais e críticas.

Nossa análise revelou a possibilidade de uma modificação na maneira de ver e de se enxergar como latino-americano, reiterando a ideia de que a construção 
da identidade latino-americana se baseia no resultado de constantes negociações, assimilações e repulsas, encontros e confrontos com os outros.

\section{REFERÊNCIAS}

BRASIL. Ministério da Educação. Secretaria de Educação Básica. Parâmetros Curriculares Nacionais: Ensino Médio. Brasília, DF, 2000.

CARMONA, BETH. TV pública no Brasil: um sonho possível? RevistaD’ART 48, 2008. São Paulo. Disponível em: <www.centrocultural.sp.gov.br/revista_dart/pdfs/dart12\%20tv\%20publica\%20no\%20brasil\%20um\%20sonho\%20possivel.pdf>. Acesso em 29 de jan. de 2020.

CASTELLS, M. O poder da identidade. $2^{a}$ ed. São Paulo: Paz e Terra, 1999.

CRUZ, M. L. O. B.; SOUZA, FM.; GAMA, A. P. F. O cinema no aperfeiçoamento das competências de línguas (materna e estrangeira). In: PROGRAD UNESP (Org.). Livro eletrônico dos núcleos de ensino da UNESP. São Paulo: Cultura acadêmica editora, 2007, pp. 487-499.

GARCÍA CANCLINI, N. Culturas híbridas: estratégias para entrar e sair da modernidade. $4^{a}$ ed. São Paulo: EDUSP, 2008.

HALL, S. A identidade cultural na pós-modernidade. Traduzido por Tomaz Tadeu da Silva e Guacira Lopes Louro. 12 ${ }^{\mathrm{a}}$ ed. Rio de Janeiro: DP\&A, 2015.

HALL, S.; JEFFERSON, T. Resistence through rituals: youth subcultures in post-war Britain. London: Hutchinson, 1977 apud GIROUX, H. Teoria critica e resistência em educação para além das teorias de reprodução. Petrópolis: Vozes, 1986.

IRINEU, L. M. Representações sociais sobre a latinidade em sites de redes sociais contemporâneas: uma investigação discursivo-ideológica situada no Orkut. Dissertação de Mestrado em Linguística. Departamento de Letras Vernáculas, Universidade Federal do Ceará, Fortaleza, 2011.

LARRAÍN, J. La identidad latinoamericana: teoría e historia. Estudios Públicos, CEP Santiago, v. 55, p. 31-64, 1994.

LESSA, G da S. M. Memórias e identidades latino-americanas invisíveis e silenciadas no ensino-aprendizagem de espanhol e o papel do professor. In: ZOLIN-VESZ, F. (Org.). A (In)Visibilidade da América Latina no ensino de espanhol. Campinas: Pontes Editores, 2013, pp. 17-27.

MENDES, E. Aprender a ser e a viver com o outro: materiais didáticos interculturais para o ensino de português LE/L2. In: SCHEYERL, D.; SIQUEIRA, S. Materiais 
didáticos para o ensino de línguas na contemporaneidade: contestações e proposições. Salvador: EDUFBA, 2012, pp. 355-378.

MIGNOLO, W. La idea de América Latina: la herida colonial y la opción decolonial. Barcelona: Editorail Gedisa, 2005.

MOITA LOPEZ (2003) Apud ORTIZ-ALVAREZ, M. L. (Des)construção da identidade latino-americana: heranças do passado e desafios futuros. Revista Intercâmbio dos Congressos Internacionais de Humanidades (UnB), Brasília, 2010.

PARAQUETT, M. Multiculturalismo, interculturalismo e ensino/aprendizagem de espanhol para brasileiros In: BRASIL, Ministério da Educação. Coleção Explorando o Ensino. V. 16. Espanhol: ensino médio. (Org.) BARROS, Cristiano Silva de e Costa, Elzimar Goettenauer de Marins. Brasília. Secretaria de Educação Básica. 2010. pp. 137-156.

RAMOS, V. H. La identidad latinoamericana: proceso contradictorio de su construcción-deconstrucción-reconfiguración dentro de contextos globales. Universitas humanística, Bogotá, n. 73, enero-junio, 2012, pp. 15-58.

REIS, L. Conversas ao sul: ensaios sobre literatura e cultura latino-americana. Niterói: EdUFF, 2009.

SILVA, T. T. da. A produção social da identidade e da diferença. In: SILVA, T. T. da (Org.). Identidade e diferença: a perspectiva dos estudos culturais. Petrópolis, RJ: Vozes, 2014, pp. 73-102.

VIDAL, NURIA. Qué tan lejos. Fotogramas, 26 de maio de 2008. Disponível em: <https://www.fotogramas.es/peliculas-criticas/a7838/que-tan-lejos/>. Acesso em: 21 de jan. de 2020. 